\title{
Article \\ Sintered Glass-Ceramics, Self-Glazed Materials and Foams from Metallurgical Waste Slag
}

\author{
Nicolai B. Jordanov ${ }^{1}$, Ivan Georgiev ${ }^{2}$ and Alexander Karamanov ${ }^{1, *}$ \\ 1 Institute for Physical Chemistry, Bulgarian Academy of Sciences, IPC-BAS, Bl. 11, Acad. G. Bonchev Str., \\ 1113 Sofia, Bulgaria; njordanov@ipc.bas.bg \\ 2 Institute for Information and Communication Technologies, Bulgarian Academy of Sciences, IICT-BAS, Bl. 2, \\ Acad. G. Bonchev Str., 1113 Sofia, Bulgaria; ivan.georgiev@parallel.bas.bg \\ * Correspondence: karama@ipc.bas.bg; Tel.: +359-2-979-2565
}

check for updates

Citation: Jordanov, N.B.; Georgiev, I.;

Karamanov, A. Sintered

Glass-Ceramics, Self-Glazed

Materials and Foams from

Metallurgical Waste Slag. Materials

2021, 14, 2263. https://doi.org/

$10.3390 /$ ma14092263

Academic Editor: Thomas Fiedler

Received: 31 March 2021

Accepted: 26 April 2021

Published: 27 April 2021

Publisher's Note: MDPI stays neutral with regard to jurisdictional claims in published maps and institutional affiliations.

Copyright: (C) 2021 by the authors. Licensee MDPI, Basel, Switzerland. This article is an open access article distributed under the terms and conditions of the Creative Commons Attribution (CC BY) license (https:/ / creativecommons.org/licenses/by/ $4.0 /)$.

\begin{abstract}
The materials used for the synthesis of parent glass are 70\% wt. metallurgical slag and 30\% wt. industrial quartz sand. The initial batch is melted at and then quenched in water. The resulting glass frit is milled bellow 75 microns and pressed $1400^{\circ} \mathrm{C}$ into "green" samples. In a next stage, they are heat treated at different temperatures with various heating rates and holding times. As a result, it is demonstrated the possibility for production variations, allowing the manufacture of three types of new materials by using the same pressed glass powders. We highlight the flexibility of the synthesis obtaining namely well densified glass-ceramics at about $950{ }^{\circ} \mathrm{C}$, self-glazed glass-ceramics at about $1000^{\circ} \mathrm{C}$ or glass-ceramic foams at approximately $1100^{\circ} \mathrm{C}$. The first set of materials is characterized by very well sintered structure combined with reasonable crystallinity; the second one-by smooth self-glazed surface with an attractive appearance and good properties and the third one-by $80-90 \%$ closed porosity and very good thermal stability above $1000{ }^{\circ} \mathrm{C}$.
\end{abstract}

Keywords: foams; waste materials; sintering; hot-stage microscopy

\section{Introduction}

Metallurgical companies worldwide provide waste streams in the form of different slags which can be recycled. One of the possibilities is they are mixed with the appropriate additives and vitrified. Then, after appropriate heat-treatment, the resulting glasses or frits are converted into final products such as traditional bulk glass-ceramics [1], sintered glass-ceramics [2,3] and glass-ceramic foams [4]. This approach can be considered as a smart tool for the solution of problems concerning the storage and immobilization of various inorganic wastes $[5,6]$. From a historical point of view, first, different materials with bulk crystallization were developed, while in recent decades, intensive research was given to the sintered glass-ceramics and foams.

Traditionally, glass-ceramic foams are prepared by the addition of inorganic carbonates or silicon carbide $(\mathrm{SiC})[7,8]$ to the press powders in order for foaming to be initiated. A similar bloating process is also commonly used for the production of lightweight ceramic foam materials [9-11]. This can be considered as the classical way of obtaining inorganic foams.

Another case, for instance, is foaming due to the oxygen release during thermal reduction of transition metals oxides. Most often, these are iron [12] and/or manganese [13] oxides.

The latter is exactly the case presented here where it is interesting to highlight the feature of the used slag. It naturally contains iron oxides and manganese oxides simultaneously. A mechanism of auto-catalytic foam formation is realized here. In the current particular case, the formation of glass-ceramic foams is related to the release of oxygen gas as a result of the reduction of both $\mathrm{Fe}(\mathrm{III})$ oxide down to $\mathrm{Fe}(\mathrm{II})$ oxide at higher temperatures 
$\left(2 \mathrm{Fe}_{2} \mathrm{O}_{3} \leftrightarrow 4 \mathrm{FeO}+\mathrm{O}_{2} \uparrow\right)$ [14] and the partial thermal reduction of $\mathrm{Mn}(\mathrm{IV})$ oxide down to $\mathrm{Mn}(\mathrm{III})$ oxide $\left(4 \mathrm{MnO}_{2} \leftrightarrow 2 \mathrm{Mn}_{2} \mathrm{O}_{3}+\mathrm{O}_{2} \uparrow\right)$ [13].

The auto-catalytic bloating phenomenon performs at relatively low viscosity and temperatures above the softening point. This leads to the formation of a high amount of pores which takes place by retention of gas within the bulk [15]. However, at lower temperature, before the beginning of bloating, well sintered material can be obtained.

The aim of the presented investigation is to demonstrate the possibilities for production of various glass-ceramic products from waste raw materials with different applications within a single production line using the same initial glass powder by application of different firing regimes. In this way, various materials, with different structure depending on the heating temperatures and rates, can be obtained.

\section{Materials and Methods}

An iron and manganese containing slag from the iron and steel company Helwan in Cairo Governorate, Eqypt was used for the thermal synthesis of the investigated glassceramic samples. Due to the low amount of main glass-formers $\left(\mathrm{SiO}_{2}+\mathrm{Al}_{2} \mathrm{O}_{3} \approx 35 \% \mathrm{wt}\right.$.) in the slag, 30\% wt. industrial quartz sand were added to $70 \% \mathrm{wt}$. slag. Thus, the percentage of the glass formers reached about $55 \%$ wt., which guarantees good chemical durability together with a moderate melting temperature of $1400^{\circ} \mathrm{C}$. It can be noted that the presence of high amounts of amorphous phase in the slag also favorizes the melting. The exact procedure concerning the glass melting was explained in our previous work [16].

After $2 \mathrm{~h}$ of holding, the melt was quenched in water. The resulting glassy frit was characterized with the following chemical composition in \% wt. determined by XRF measurement: $49.2 \mathrm{SiO}_{2} ; 5.1 \mathrm{Al}_{2} \mathrm{O}_{3} ; 5.5 \mathrm{Fe}_{2} \mathrm{O}_{3} ; 18.6 \mathrm{CaO} ; 1.1 \mathrm{MgO} ; 5.8 \mathrm{MnO} ; 10.9 \mathrm{BaO} ; 0.7$ $\mathrm{TiO}_{2} ; 0.7 \mathrm{~K}_{2} \mathrm{O}$ [16]. It is interesting to be pointed out the result that the presence of $\mathrm{Fe}$ and $\mathrm{Mn}$ in the slag is unusually high.

Thus, obtained frit was grinded with a planetary mill FRITSCH (Germany). Portions of $5 \mathrm{~g}$ each were then sieved to a fraction below 75 microns with a digitally programmed sieving machine CISA (Spain). The sieving times were programmed to10 min. Finally, the "green" samples with a parallelepiped shape of $50 \times 5 \times 4 \mathrm{~mm}$ were prepared by uniaxial pressing of the powders at $40 \mathrm{MPa}$ with a pneumatic pressing machine NANNETTI (Italy). Then, $7 \%$ wt. polyvinyl alcohol (PVA) was used as a binding agent as well.

In all investigations, we used a thermo-optical computerized system ESS ODLT HSM1400 MISURA (Italy) allowing measurements with heating rates up to $30^{\circ} \mathrm{C} \mathrm{min}{ }^{-1}$. This equipment combines two measurement techniques: horizontal contact-less optical dilatometry and vertical hot-stage microscopy (abbreviated below as ODLT and HSM as already mentioned). Both methods trace the length and height change, respectively, of the samples with different sensitivity and can be switched and used on demand. This turned out to be an established laboratory method in recent years, since it is reliable and fast and is used already by many research groups worldwide [9-11,17].

Thus, obtained samples are appropriate for studies with ODLT. Some of these samples were cut to $(6-8) \times 5 \times 4 \mathrm{~mm}$ pieces for additional thermal treatments at higher temperatures.

In particular, ODLT was used toward the investigations of the process of sintering while HSM was used for the sake of a general overall investigation of the high temperature thermal treatment behavior and for tracking of the foaming process.

Other green smaller samples, suitable for direct HSM measurements, with standard cylindrical shape of $5 \mathrm{~mm}$ height and $2 \mathrm{~mm}$ diameter, were prepared by manually pressing with a manual plunger and distilled water as a binder.

The following types of measurements were performed for the purpose of process optimization by means of adjusting thermal scan rates, firing temperatures and for a detailed investigation of the studied processes: 1 . Non-isothermal and isothermal HSM scanning of the small manually pressed samples; 2 . Isothermal ODLT measurements in the 
temperature range of $900-950{ }^{\circ} \mathrm{C}$ using $50 \mathrm{~mm}$ samples; 3 . Preparation of self-glazed and foamed cut samples at short holding times and higher temperatures.

Scanning electron microscopy (SEM) images of surfaces and fractures of the sintered glass-ceramics were taken with a JEOL 6390 (Japan) microscope. Following the laboratory procedure proposed by Strnad [18], the bulk samples were polished and etched $5 \mathrm{~s}$ each in a $2 \%$ wt. aqueous solution of hydrofluoric acid (HF).

The phase composition of the powdered sintered glass-ceramics was determined by $\mathrm{X}$-ray diffraction spectroscopy (XRD) with a PANALYTICAL EMPYREAN (USA) spectrometer.

Finally, the entire bulk structure of the newly formed sintered material was studied by 3D X-ray tomographic analysis. In this case, industrial computed tomographic imaging $(\mu \mathrm{CT})$ was carried out with a Nikon XT H 225 system, developed by Nikon Metrology. Each sample was rotated on $360^{\circ}$ and 2520 digital radiographic projections were acquired during the rotation. The Inspect-X CT software was used to control the acquisition process. The scanning of the samples was performed with a voltage of $110 \mathrm{kV}, 100 \mu \mathrm{A}$ tube current and exposure time of $500 \mathrm{~ms}$. The size of the voxel was $4 \mu \mathrm{m}$. The volume reconstructions were performed by CT Pro 3D software developed by the producer of the equipment. Volume rendering, porosity analysis and measurements were performed by VG Studio Max 2.2 software by Volume Graphics Inc. (Heidelberg, Germany)

When we have foams of irregular structure, arbitrary shape and broad cell volume distribution the $\mu \mathrm{CT}$ scanning turns out to be the most proper method toward the nondestructive characterization of cellular materials $[19,20]$.

\section{Results and Discussion}

In Figure 1, is presented a typical HSM curve of the variation of the height of a single press-powder sample in the domain thermal expansion-temperature.

Additionally, in Figure 1a-e, characteristic snapshots are indicated during the thermal cycle presented in Figure 1. In this manner, the possibility to obtain different materials is demonstrated. In Figure 1a, the thermal propagation is shown with a snapshot at $700{ }^{\circ} \mathrm{C}$, which is practically identical with the initial sample. The densification process starts at about $800{ }^{\circ} \mathrm{C}$ and the sintering of the glass-ceramics is completed at about $900{ }^{\circ} \mathrm{C}$ as it is shown in Figure $1 \mathrm{~b}$. Further scanning up to $1050{ }^{\circ} \mathrm{C}$ led to no serious change in the volume of the sample. At this temperature, however, some certain smoothing of the shape is observed and after that, initiates the beginning of the foaming process. Further, Figure 1c corresponds to material formation characterized with smooth auto-glazed surface due to the fact that this temperature is slightly above the HSM softening point [21,22].

In Figure $1 \mathrm{~d}$, the shape is demonstrated at $1150{ }^{\circ} \mathrm{C}$, which corresponds to maximal extent of bloating during foaming. Further increase of the temperature up to $1200{ }^{\circ} \mathrm{C}$ as indicated in Figure 1e leads to a rapid structural shrinkage and collapse of the foam. The sample reveals a nearly spherical silhouette (c.f. Figure 1e) which means that at this temperature, the gas release is completed and the apparent viscosity decreases due to the melting of the formed at heating crystal phases. This assumption was established with DTA in our previous work [16].

It can be highlighted that the HSM measurements reveal three well distinguished temperature intervals for synthesis of three different types of new materials.

At low temperature, before the beginning of the foaming sintered glass-ceramics was investigated.

The densification and the crystallization are two major competing processes during thermal treatment of sintered glass-ceramic products. Both should be balanced very carefully in tuning the synthesis since one should consider the close temperature interval where both processes are taking place.

The sintering ability of glass powders is a key feature characterizing the manufacturing of these glass-ceramics. In principle, it is favored by using finer powder fractions and/or the implementation of higher heating scan rates. In this manner, the inhibiting effect of the crystallization on the densification can be reduced. 


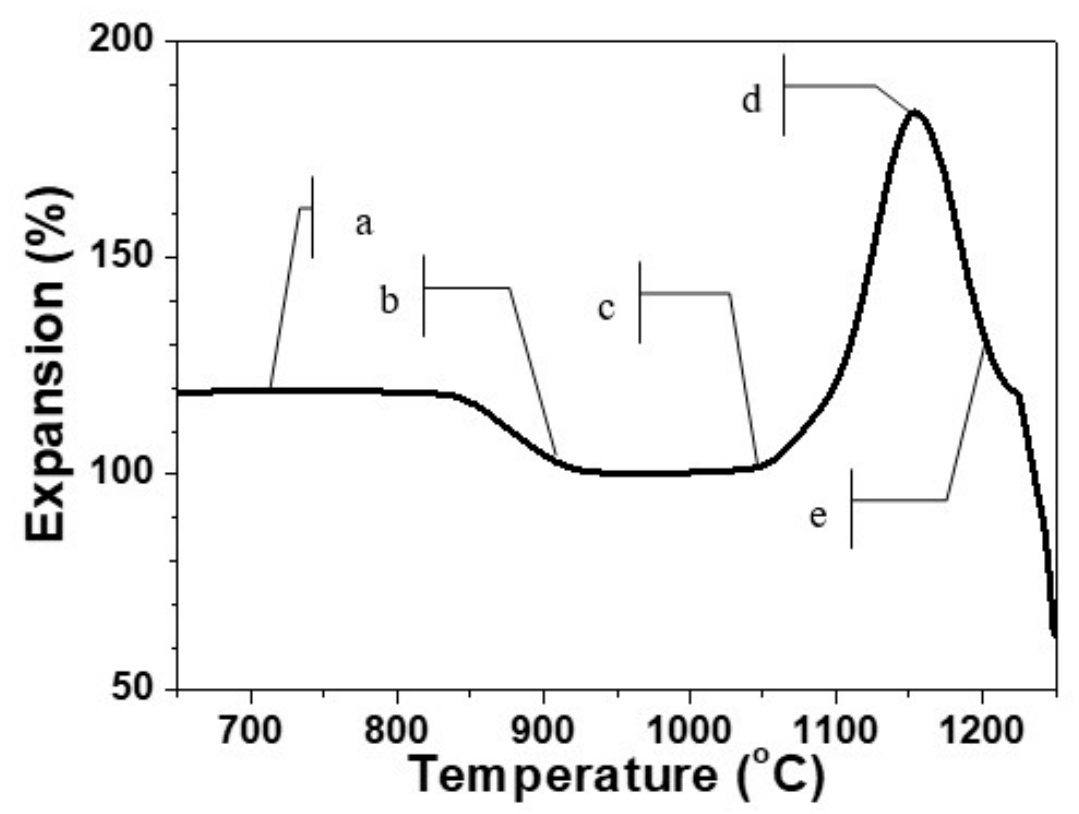

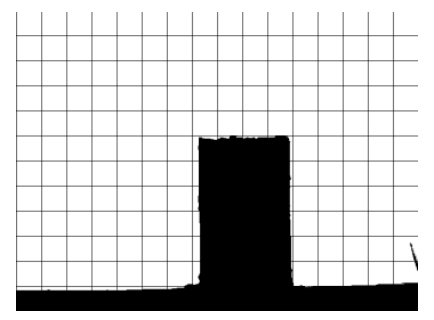

(a)

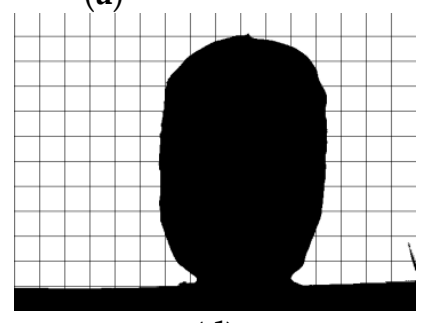

(d)

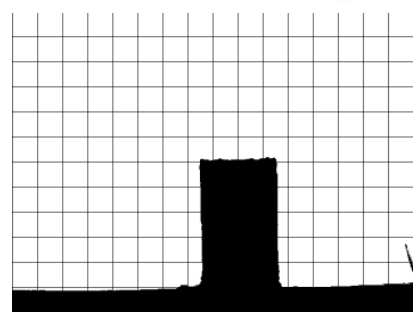

(b)

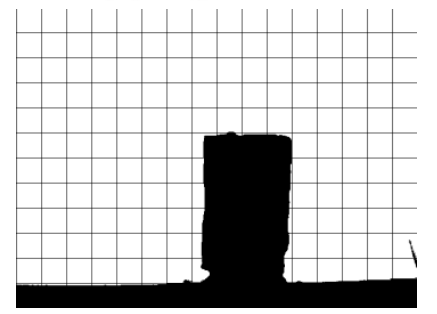

(c)

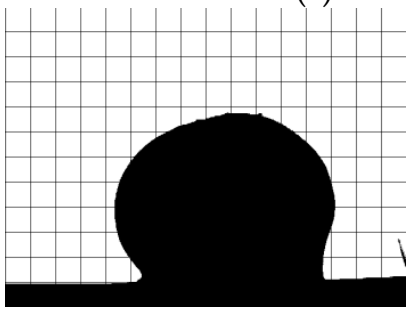

(e)

Figure 1. HSM curve of glass ceramic sample at $10{ }^{\circ} \mathrm{C} \mathrm{min}^{-1}$. Figure 1a-e: profile optical images of the glass-ceramics at the respective temperature of $700^{\circ} \mathrm{C}(\mathbf{a}), 900^{\circ} \mathrm{C}(\mathbf{b}), 1050^{\circ} \mathrm{C}(\mathbf{c}), 1150{ }^{\circ} \mathrm{C}(\mathbf{d})$ and $1200{ }^{\circ} \mathrm{C}(\mathbf{e})$.

The second key factor is the crystallization process. It is well known that if the composition possesses a low crystallization ability, the densification can be explained with the theory of viscous flow sintering. On the contrary, in the case of higher crystallization trend, the latter can partially inhibit the sintering.

At the same time, the firing regimes can guarantee the completion of the crystallization process. The resulting precipitation is higher at lower crystallization temperature, which can lead to bigger percentage of formed crystal phases [5,23]. However, at lower temperatures, the crystallization times are longer.

For instance, the relationship between densification and new phase formation was elucidated in our previous work [16]. We investigated the effect of $\mathrm{CaF}_{2}$ on the sintering ability and the foaming trend of the same base glass studied there (with different additions of $\mathrm{CaF}_{2}$ ). In small quantities, due to viscosity diminishing, $\mathrm{CaF}_{2}$ decreases the sintering and the melting temperatures, while in larger quantities, it blocks the sintering and inhibits the foaming of the sample.

With the increase of the temperature in the composition without $\mathrm{CaF}_{2}$, which is the case under discussion, deformation starts, followed by bloating, which is related to the 
presence of iron and manganese oxides in the parent glass. This gives the possibility of foam glass-ceramics to be studied.

The mechanism of bloating by Fe(III) oxide reduction is well known. Sandrolini and Palmonary, 1976 [9], provided a detailed description of the key role of iron oxides in the foaming of vitrified sintered ceramic materials. At elevated temperatures, $\mathrm{Fe}_{2} \mathrm{O}_{3}$ is partially reduced with the release of oxygen as the bloating gaseous phase. The latter generates large pores within the fired body and determines a density decrease [15].

The auto-catalytic foaming can be explained with the variation of the ratio of the oxidation state of the transition metal oxides with temperature. The higher the temperature, the lower the amount of the reduced form.

It can be mentioned that during quenching of the melt into frit, an equilibrium ratio of the redox couple $\mathrm{Fe}(\mathrm{II}) \leftrightarrow \mathrm{Fe}(\mathrm{III})$ was "frozen" (fixed) in the glass. In this case, it corresponds to the equilibrium value of the melting temperature.

However, above the glass transition temperature, oxidation takes place. This practically leads to complete oxidation of $\mathrm{Fe}(\mathrm{II})$ into $\mathrm{Fe}(\mathrm{III})$ [24,25]. With further temperature increase, the reduction initiates again. It is interesting to note that when the heat treatment is carried out in an inert atmosphere, no oxidation and subsequent reduction related with foaming is observed [14].

So that with temperature variation and with the related viscosity and oxi-reduction processes, the production of different sintered glass-ceramic materials is possible.

\subsection{Synthesis and Characterization of Sintered Glass-Ceramic Materials}

The low temperature sintering behavior of a studied glass-ceramic sample is presented in Figure 2. Results are obtained at the isothermal heat treatment step at the optimal temperature of $950{ }^{\circ} \mathrm{C}$ and with a holding time of 30 min using a modest heating rate of $10{ }^{\circ} \mathrm{C}$ $\mathrm{min}^{-1}$. The densification interval is indicated by the shaded area. This result highlights that the sample shrinks by $13 \%$ and that the sintering process is entirely completed already in the beginning of the non-isothermal step (we have $12 \%$ linear shrinkage during heating and only $1 \%$ taking place during the first $5 \mathrm{~min}$ of the hold). It is important to note that during the remaining $25 \mathrm{~min}$, no volume changes have been observed, i.e., no deformation is carried out during the crystallization step. We have to mention additionally that at lower temperatures $[5,15,23]$, longer crystallization times can be applied.

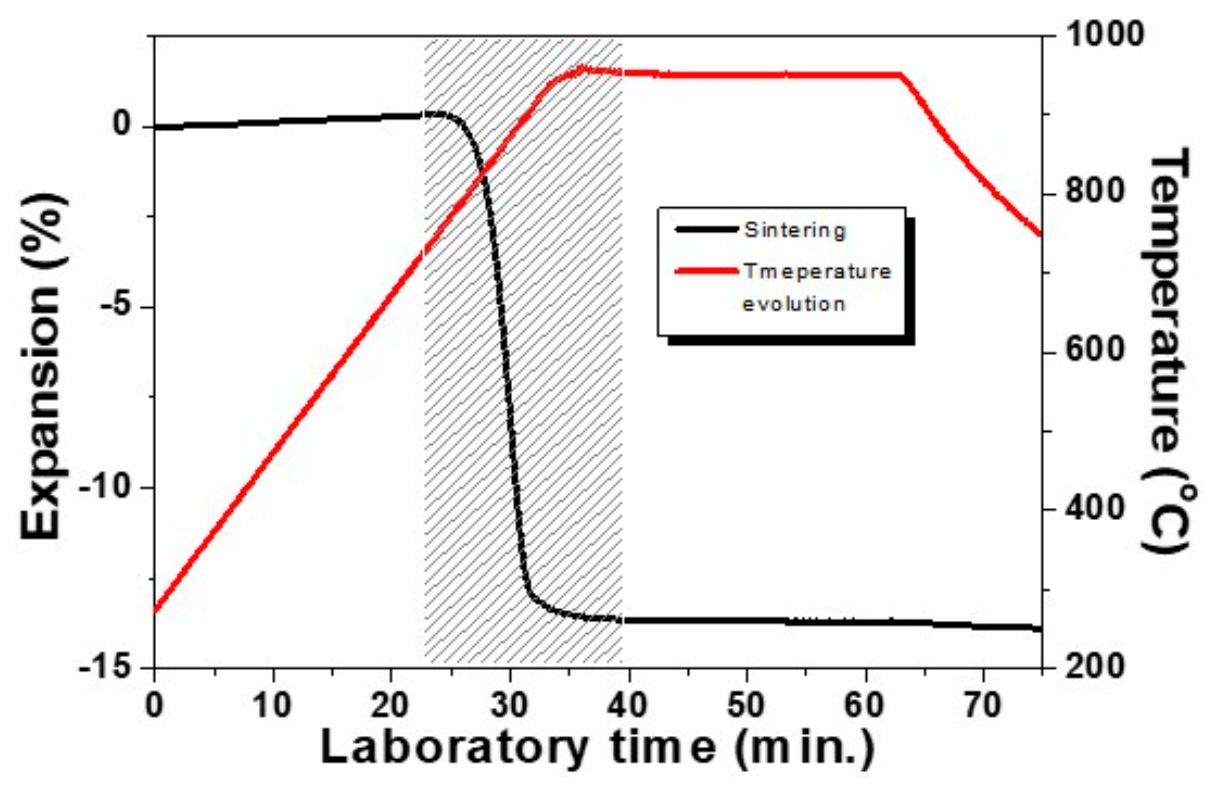

Figure 2. Sintering curve of glass-ceramic sample revealed by HSM. 
The complete crystallization process for $30 \mathrm{~min}$ at $950{ }^{\circ} \mathrm{C}$ has been confirmed by XRD measurements. In Figure 3, are presented XRD diffraction patterns of the initial glass (3a) and sample sinter crystallized at $950{ }^{\circ} \mathrm{C}$ for $1 \mathrm{~min}(3 \mathrm{~b})$ and for $30 \mathrm{~min}$ (3c). It is evident that during the isothermal step, some increase of crystallinity is observed and the main crystal phase is pyroxene. By comparison of the intensities of the amorphous halo of the initial glass with that of the crystallized sample for $30 \mathrm{~min}$ was found that the crystallinity is $35 \pm 5 \%[19]$.

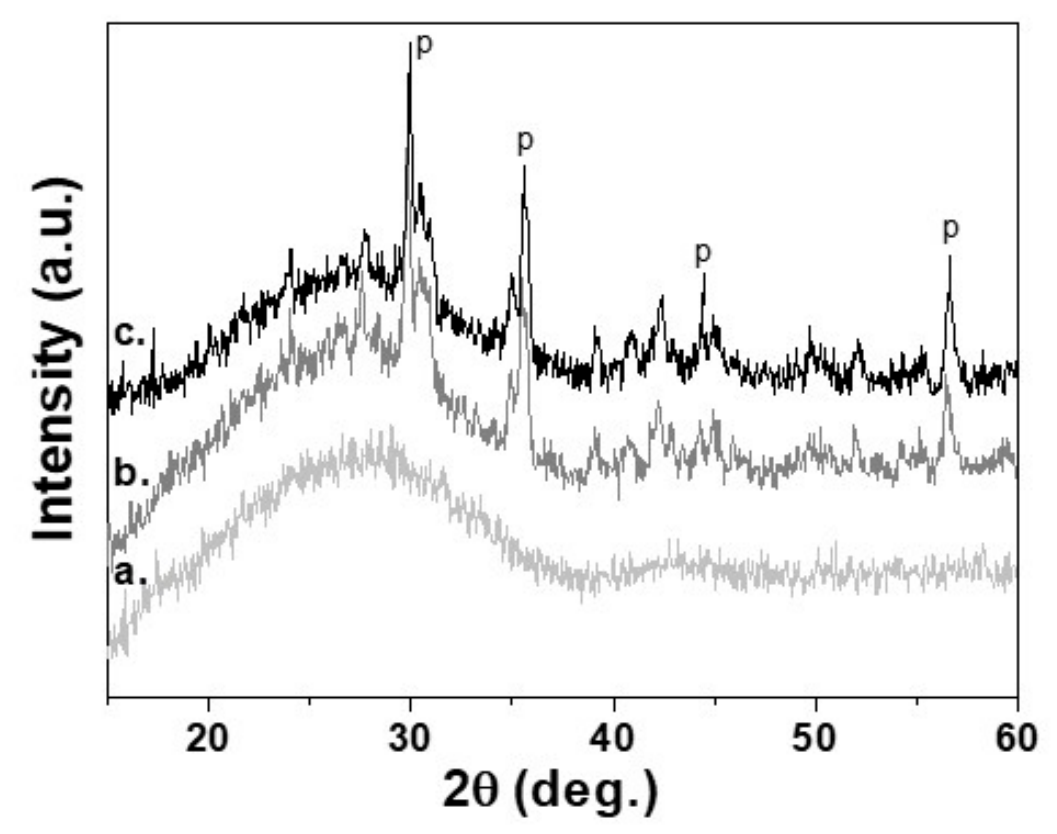

Figure 3. XRD patterns of a. Parent glass, b. Glass-ceramics isothermally sintered at $950{ }^{\circ} \mathrm{C}$ for $1 \mathrm{~min}$; c. Glass-ceramics isothermally sintered at $950{ }^{\circ} \mathrm{C}$ for $30 \mathrm{~min}$. "P" referes to the peaks of pyroxene crystal phase.

From observations of the SEM image shown in Figure 4a, one can estimate that the porosity in the bulk of the sintered new material is mainly of closed type and its amount is less than $10 \%$ vol. A typical spherical pore is presented in Figure $4 \mathrm{~b}$, while Figure $4 \mathrm{c}$ reveals a sharp-edge inter-granular porosity with visible channels between the grains. The surface is smooth and very well sintered as demonstrated in our previous recent study [14]. Nevertheless, some closed porosity with a structure similar to Figure $4 \mathrm{c}$ is elucidated (c.f. Figure 4d). The presence of such type of porosity is probably indicative for certain overlapping of both sintering and crystallization processes as it was highlighted by the isothermal sintering and XRD results.

\subsection{Synthesis and Characterization of Self-Glazed Glass-Ceramic Materials}

Figure 1 indicates that after non-isothermal heat treatment, the sintering curve up to $1000-1050{ }^{\circ} \mathrm{C}$ reveals no significant volume change. At the same time, the comparison between the silhouette snapshots in Figure 1b,c shows some smoothing of the surface due to the viscosity decrease.

Thus, the possibility to form self-glazed glass-ceramic samples was studied. If we terminate the firing at the above cited temperature interval, a well densified material with smooth auto-catalytically induced (or self-glazed) surface can be successfully obtained. This densification is enhanced by applying higher heating rates which gives a possibility to shorten the firing regime. 


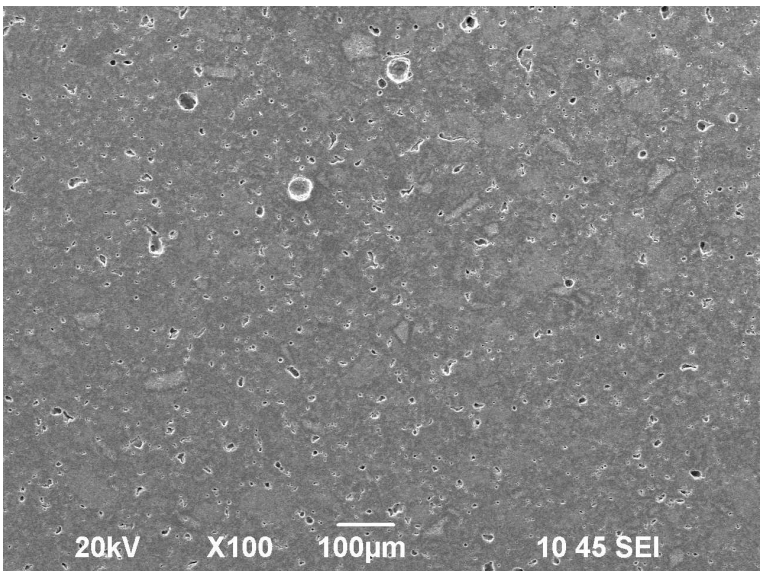

(a)

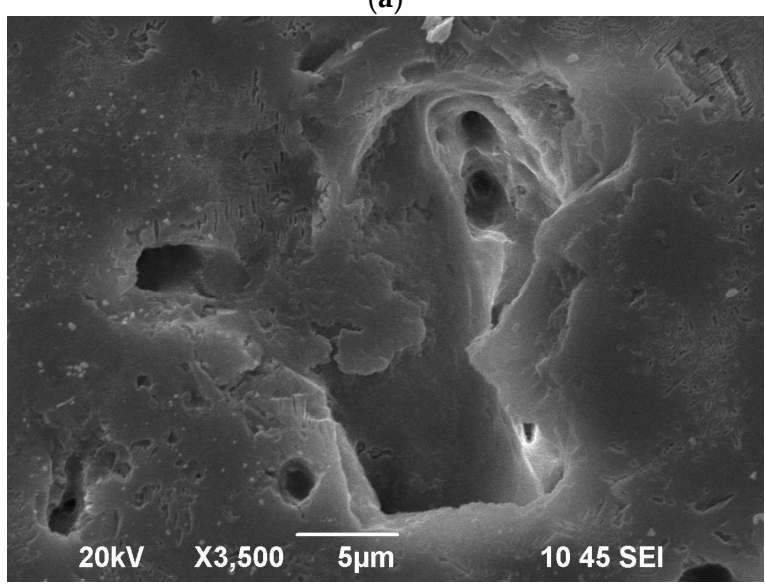

(c)

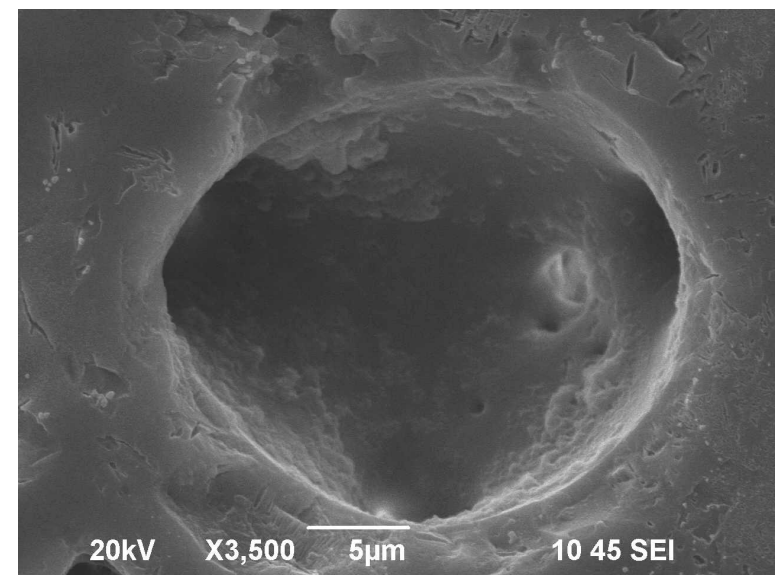

(b)

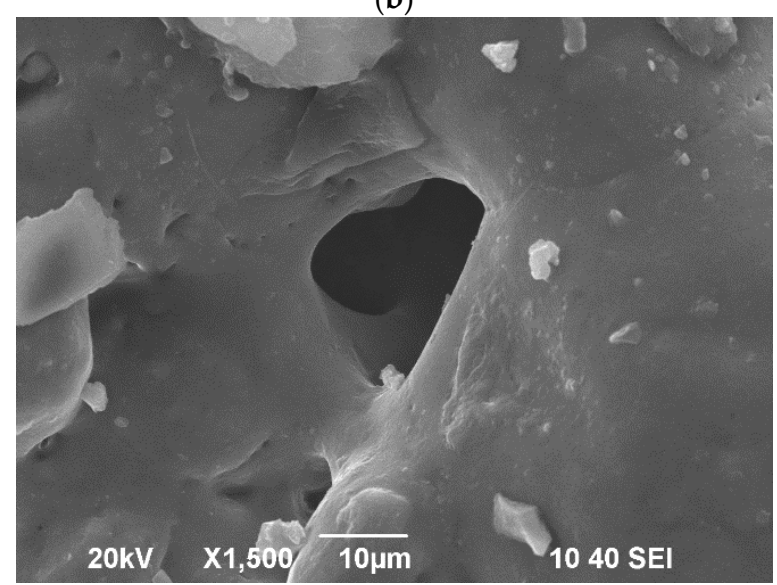

(d)

Figure 4. SEM images of polished samples at different magnifications: $(\mathbf{a}-\mathbf{c})$; Single pore formed on the surface, $(\mathbf{d})$.

In Figure 5, is shown a representative species obtained at $1020^{\circ} \mathrm{C}$ using a scan rate of $20^{\circ} \mathrm{C} \min ^{-1}$ and holding time of $3 \min [16]$.

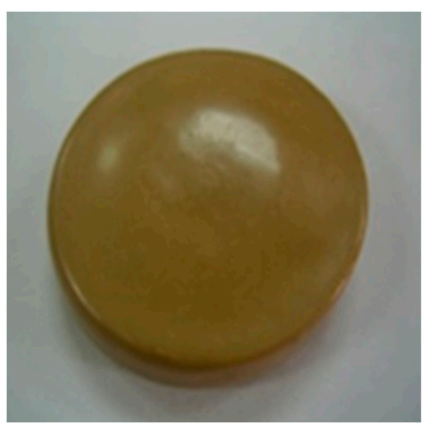

Figure 5. Color photograph of bloated iron-rich glass-ceramic sample as described in [14].

This material is characterized with zero water absorption, about $15 \%$ vol. closed porosity and good mechanical properties (apparent density of $2.22 \pm 0.05 \mathrm{~g} \mathrm{~cm}^{-3}$ and hardness of $4.71 \pm 0.01 \mathrm{GPa}$ ) and compressive strength of $140 \pm 20 \mathrm{MPa}$ [16]. These properties correspond to natural stones and some construction materials.

Working at higher temperatures and/or higher heating rates, due to the formation of lower amount of crystal phase and decreasing of the apparent viscosity some deformation (related in this particular case to auto-glazing and color change) is observed. This material is characterized with a commercial shiny appearance appropriate for e.g., decorative swimming pool tiling. 


\subsection{Synthesis and Characterization of Glass-Ceramic Foam Materials}

The production of low weight fire resisting foams is the third and final part of the current research. This is directly realized as a result due to the presence of iron oxides ( $\mathrm{FeO}$ and $\left.\mathrm{Fe}_{2} \mathrm{O}_{3}\right)$ and manganese oxides $\left(\mathrm{Mn}_{2} \mathrm{O}_{3}\right.$ and $\left.\mathrm{MnO}_{2}\right)$ in the initial glass frit.

As it was already pointed out, after almost completed oxidation of the transition metals in the glass transition region with the further increase of the temperature thermal reduction of iron and manganese starts again.

Moreover, the already reached degree of sintering is directly responsible for the subsequent foaming trend of the glass-ceramics as well, in a fashion such that, higher initial degree of sintering leads to a higher foaming ability and vice versa. This circumstance was confirmed in our previous work [14] and by other authors [12].

As a result, in well sintered glass-ceramics with closed porosity and with moderate crystallinity, which is the case of discussion, the possible structural expansion with the increase of temperature is very intensive. We highlighted also that carrying out synthesis with higher heating rates of e.g., $30^{\circ} \mathrm{C} \mathrm{min}-1$ leads to lower crystallinity and thus to lower apparent viscosity. Despite the shorter heat treatment times, the beginning of the foaming process at $30^{\circ} \mathrm{C} \mathrm{min}^{-1}$ starts at lower temperature compared to that at $5{ }^{\circ} \mathrm{C} \min ^{-1}$ [16]. Thus, in the production of the foam, compared to the synthesis of sintered glass-ceramics at $950{ }^{\circ} \mathrm{C}$, the maximal heating rate of $30^{\circ} \mathrm{C} \mathrm{min}^{-1}$ is used.

As it is shown in Figure 1, the intensive increase of the volume starts taking place at a temperature of about $1050{ }^{\circ} \mathrm{C}$ and the maximal expansion is reached at about a $100{ }^{\circ} \mathrm{C}$ higher temperature.

The appropriate regime was estimated in a series of preliminary measurements. An optimal isothermal HSM measurement with holding time of $30 \mathrm{~min}$ at $1100{ }^{\circ} \mathrm{C}$ of the formation of new glass-ceramic foam material sample ending up with its stabilization is shown in Figure 6. The snapshot selection of three characteristic pictures in Figure 6 recorded during the initial sintered state of the sample (6a), the maximum height of bloating after about $10 \mathrm{~min}$, of holding (6b) and the stabilization of the shape after about $20 \mathrm{~min}$ of a glass-ceramic foam (6c) are presented here. The observed stabilization can be explained most probably with the completion of the evolution of oxygen release. After the fixing of the shape, no change of the sample is observed at cooling. This elucidates that the material can be considered as fire resistant at temperatures below the range of $1000-1050{ }^{\circ} \mathrm{C}$.

A larger foamed sample obtained under the same optimal conditions is represented in Figure $7 \mathrm{~d}$ together with: $7 \mathrm{a}$ initial non-sintered sample; $7 \mathrm{~b}$ sintered at $950{ }^{\circ} \mathrm{C}$ at $10^{\circ} \mathrm{C} \mathrm{min}{ }^{-1}$ and $7 \mathrm{c}$, self-glazed sample. All the samples were prepared by cutting of initial bars as described in the Experiment section. The comparison between sample $7 \mathrm{~b}$ and $7 \mathrm{~d}$ shows a huge linear expansion of about four times and color variation.

The same samples were investigated further with X-ray computed tomography $(\mu \mathrm{CT})$. In the observations, were evident sub-resolution effects as well, contributions that cannot be clearly seen. Thus, the information obtained is correct only for objects larger than about $10 \mu \mathrm{m}$. The initial sample in Figure 8a is abundant with open pores of irregular shape with size up to $60-80 \mu \mathrm{m}$, i.e., their size is comparable to this of the initial particles. In Figure $8 \mathrm{~b}, \mathrm{c}$ are presented sintered glass-ceramics and sintered self-glazed samples, respectively. In both samples, the porosity is of closed type and mainly with spherical shape. However, in the second object, the maximal size of the porosity increases more than three times, reaching $80-100 \mu \mathrm{m}$. This indicates the beginning of the coalescence process which is evident mainly in the middle of the sample. Figure $8 \mathrm{~d}$ demonstrates the image of the boundary between the most dense surface layer and the volume part where the coalescence is highlighted.

Figure 9 shows the structure of the foamed sample. In $9 \mathrm{a}$, is given a 3D volume reconstruction of the whole sample, while in Figure 9b,c are shown 2D images of slices from the center part of the objects at different magnifications. 


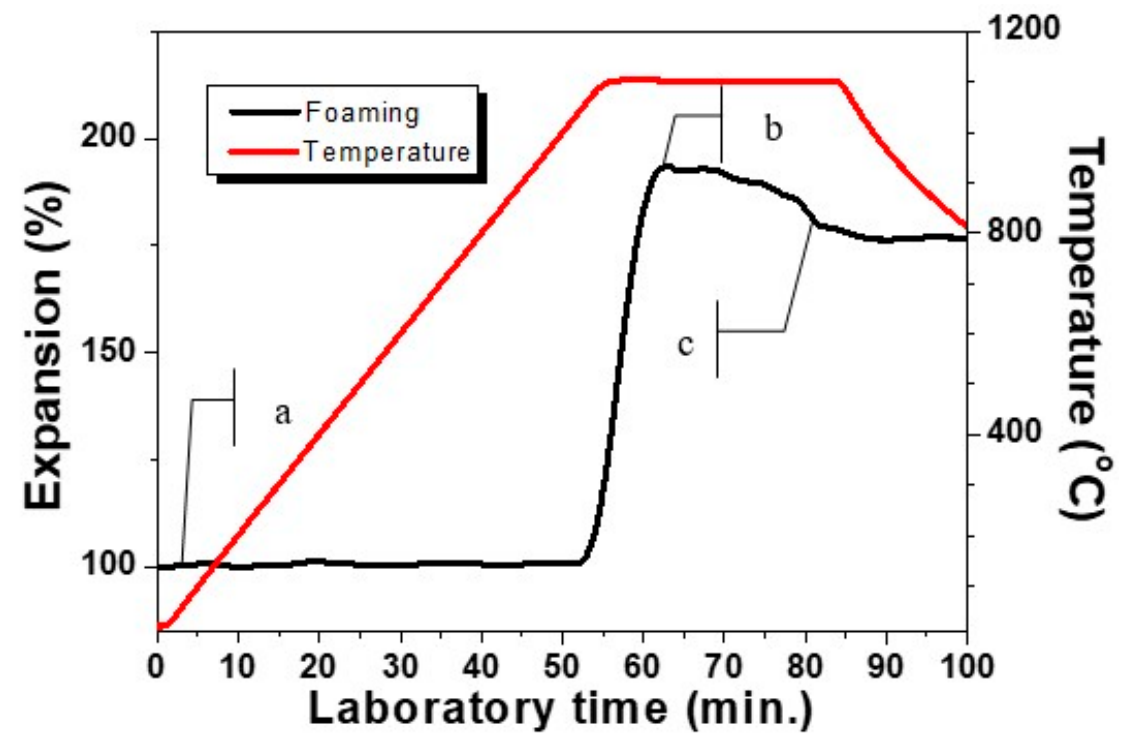

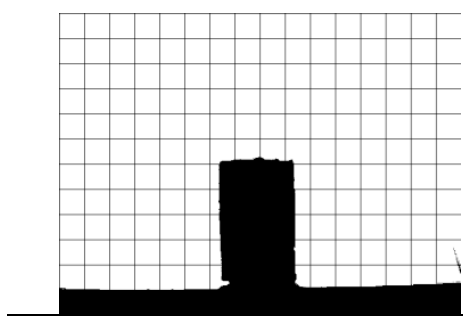

(a)

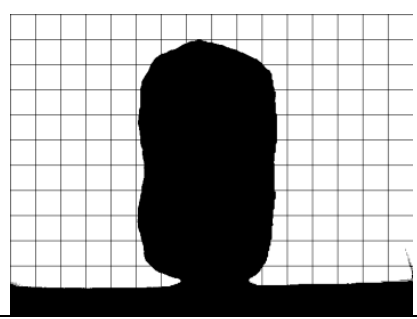

(b)

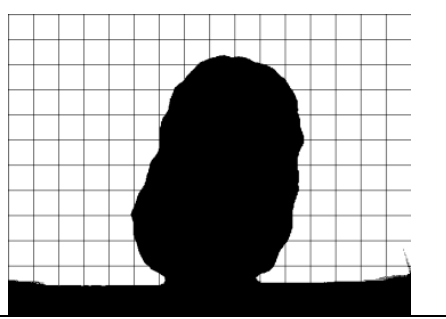

(c)

Figure 6. HSM sintering curve during the formation of a glass ceramic foam at a temperature of $1100{ }^{\circ} \mathrm{C}$; $(\mathbf{a}-\mathbf{c})$ - silhouette images during the bloating process.
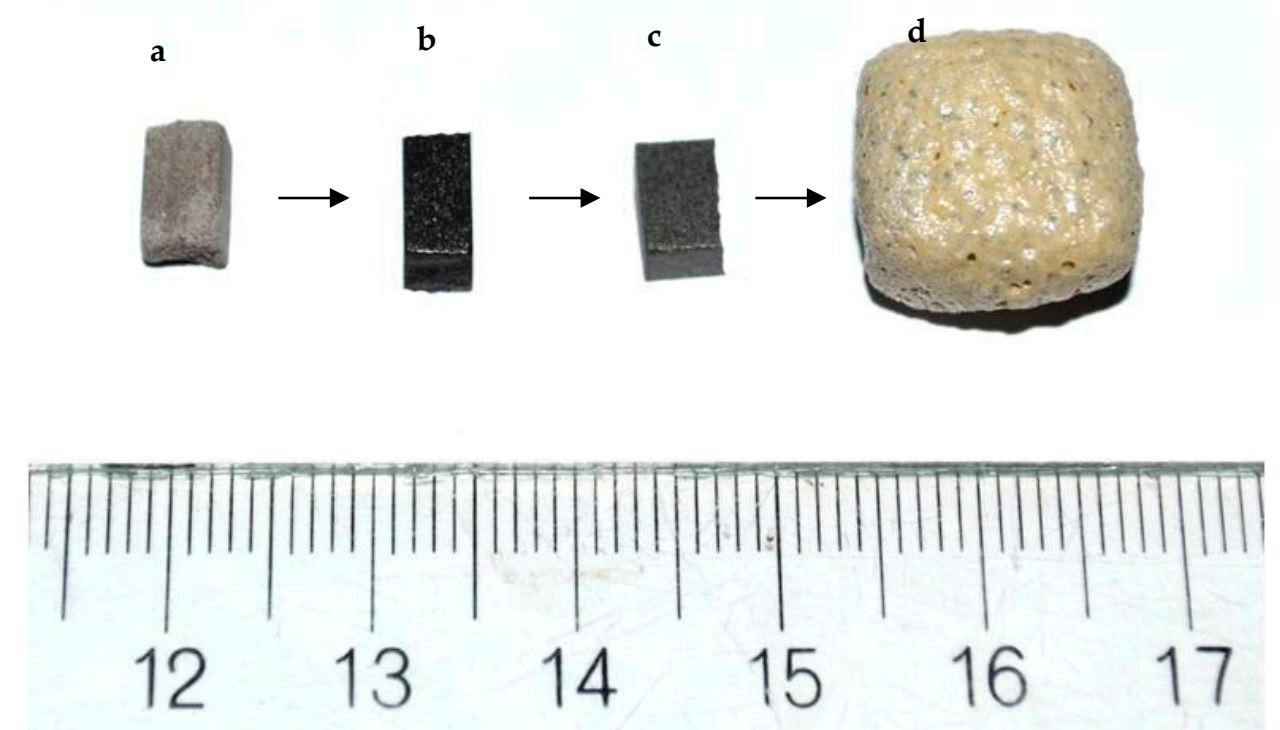

Figure 7. Photographs of the studied materials: (a) Press-powder; (b) Sintered glass-ceramics synthesized at $900{ }^{\circ} \mathrm{C}$; (c) Self-glazed glass-ceramics obtained at $1020^{\circ} \mathrm{C}$; (d) Glass-ceramic foam sample bloated at $1100{ }^{\circ} \mathrm{C}$. 

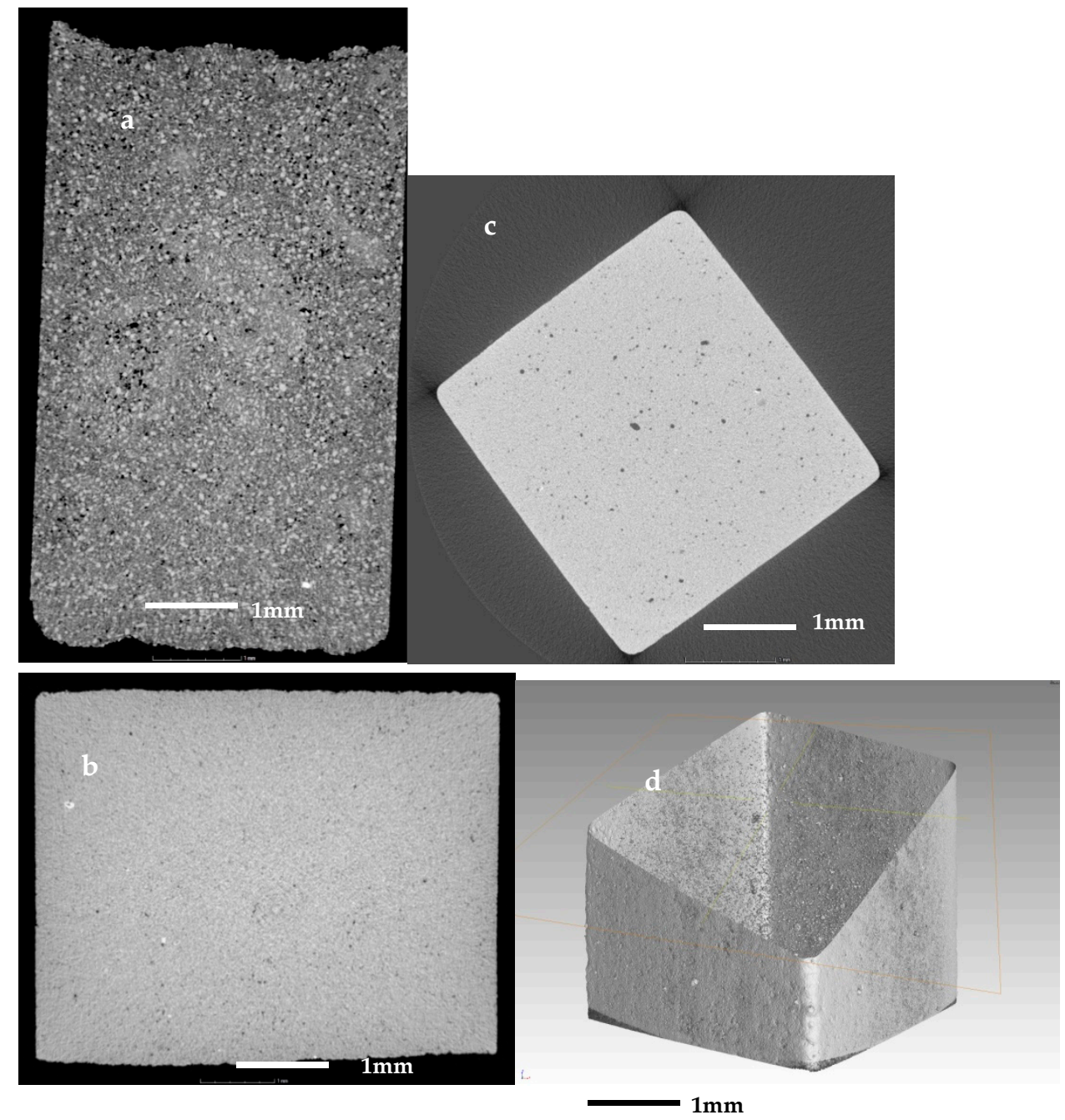

Figure 8. X-ray CT scan images of (a) the initial sample; (b) of a sintered glass-ceramics; (c,d) sintered self-glazed sample.

In Figure 9a as well as in Figure 7d, is elucidated that the specimens' surface is smooth and practically without open pores. In fact, this confirms, as indicated in our previous work [16], that the similar species does not absorb water even after $48 \mathrm{~h}$ of sinking.

The distribution and the structure of the porosity are highlighted in Figure 9b,c. We may note that there are two main types of pores: primary large pores and secondary fine pores abundant in the walls of the foam. The structure of the foam is cellular with a nearly spherical porosity. The primary pores are sized between 500 and $2000 \mu \mathrm{m}$, while the secondary are mainly of sizes between 50 and $100 \mu \mathrm{m}$.

Probably the formation of secondary pores is related to a more complex reduction process involving iron and manganese reduction. In fact, in traditional ceramics and glass-ceramics foams, such an intriguing structure was not observed [26-28].

The 3D reconstruction of the sample also gives the possibility to evaluate the total porosity. The measurement of the volumes of the whole sample and that of the total solid substance produces porosity percentage in the range of $85-90 \%$ vol., which is a very reasonable value. 

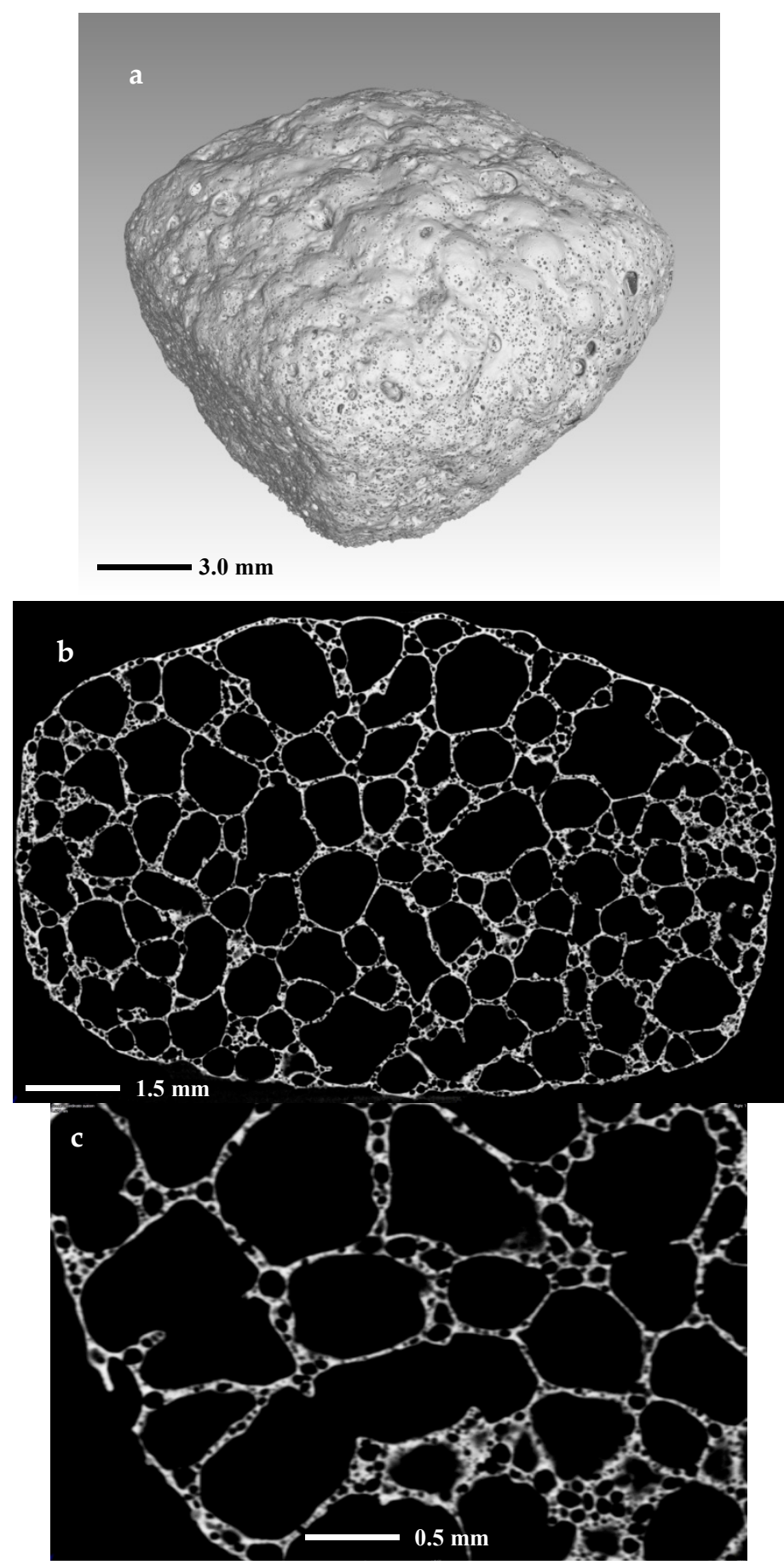

Figure 9. X-ray CT scan images of (a) 3D reconstruction of foam sample; (b,c) 2D intersection.

\section{Conclusions}

In the present investigation, we demonstrated the possibility for carrying out successful synthesis of different sintered materials obtained from the same glass, products of vitrification of metallurgical slag. By variation of the used firing regime, generally speaking, we discuss the possibility for manufacturing the following three types of materials: 1. sintered glass-ceramic; 2 . self-glazed material; 3 . glass-ceramic foam.

The demonstrated technological flexibility is controlled by the heat treatment rates and holding temperatures because of the variations of the crystallinity and of the apparent 
viscosity, as well as by the bloating tendency due to the thermal reduction of iron and manganese oxides present in the used slag.

By using a heating rate of $10{ }^{\circ} \mathrm{C} \mathrm{min}^{-1}$ and heat treatment of $950{ }^{\circ} \mathrm{C}$, we obtain well sintered glass-ceramics characterized with about $10 \%$ vol. porosity and moderate crystallinity of about $35 \%$.

Applying higher rates of $20^{\circ} \mathrm{C} \mathrm{min}^{-1}$ and short holding times at $1020^{\circ} \mathrm{C}$, we obtain a product with slightly misshapen surface in the form of self-glazing with very pleasant to the eye smooth surface.

Finally, at thermal scan rates of e.g., $30{ }^{\circ} \mathrm{C} \mathrm{min}^{-1}$ and holding at temperatures of $1100{ }^{\circ} \mathrm{C}$, allows us to obtain new fire-resisting sintered glass-ceramic foams with cellular structure and closed porosity of about $85-90 \%$.

Author Contributions: The idea of current research is of both N.B.J. and A.K. N.B.J. is responsible for the text writing, figure production and layout. A.K. and N.B.J. are both responsible for text editing. I.G. is responsible for 3D CT imaging of the sintered materials samples. All authors have read and agreed to the published version of the manuscript.

Funding: This research received no external funding.

Institutional Review Board Statement: The study was conducted according to the guidelines of the Declaration of Helsinki, involving no humans or animals by any means.

Informed Consent Statement: Informed consent was obtained from all subjects.

Data Availability Statement: https: / /www.intechopen.com/books / foams-emerging-technologies / sintered-iron-rich-glass-ceramics-and-foams-obtained-in-air-and-argon (accessed on 27 April 2021).

Acknowledgments: N.B. Jordanov gratefully acknowledges the financial support of the National Program Young Scientists and Post-docs of the Ministry of Education and Science of Republic of Bulgaria under the project "Sintered self-glazed glass-ceramics and foams from iron-rich industrial wastes". All authors express their gratitude for the support of Project BG05M2OP001-1.002-0019: "Clean technologies for sustainable environment-waters, waste, energy for circular economy." and of Project of the Bulgarian Science Fund, FNI, KP-06-N27/14. Many thanks to E. M. A. Hamzawy for glass melting and for characterization of the self-glazed samples.

Conflicts of Interest: We the authors declare no conflict of interests.

\section{References}

1. Wang, Z.-J.; Ni, W.; Li, K.-Q.; Huang, X.-Y.; Zhu, L.-P. Crystallization characteristics of iron-rich glass ceramics prepared from nickel slag and blast furnace slag. Int. J. Miner. Met. Mater. 2011, 18, 455-459. [CrossRef]

2. Öveçoğlu, M. Microstructural characterization and physical properties of a slag-based glass-ceramic crystallized at 950 and $1100{ }^{\circ}$ C. J. Eur. Ceram. Soc. 1998, 18, 161-168. [CrossRef]

3. Monich, P.R.; Vollprecht, D.; Bernardo, E. Dense glass-ceramics by fast sinter-crystallization of mixtures of waste-derived glasses. Int. J. Appl. Ceram. Technol. 2019, 17, 55-63. [CrossRef]

4. Monich, P.R.; Romero, A.R.; Höllen, D.; Bernardo, E. Porous glass-ceramics from alkali activation and sinter-crystallization of mixtures of waste glass and residues from plasma processing of municipal solid waste. J. Clean. Prod. 2018, 188, 871-878. [CrossRef]

5. Romero, M.; Rincón, J. Preparation and properties of high iron oxide content glasses obtained from industrial wastes. J. Eur. Ceram. Soc. 1998, 18, 153-160. [CrossRef]

6. Khater, G. Influence of $\mathrm{Cr}_{2} \mathrm{O}_{3}, \mathrm{LiF}, \mathrm{CaF}_{2}$ and $\mathrm{TiO}_{2}$ nucleants on the crystallization behavior and microstructure of glass-ceramics based on blast-furnace slag. Ceram. Int. 2011, 37, 2193-2199. [CrossRef]

7. Rincón, A.; Marangoni, M.; Cetin, S.; Bernardo, E. Recycling of inorganic waste in monolithic and cellular glass-based materials for structural and functional applications. J. Chem. Technol. Biotechnol. 2016, 91, 1946-1961. [CrossRef] [PubMed]

8. Scarinci, G.; Brusatin, G.; Bernardo, E. Glass foams. In Cellular Ceramics: Structure, Manufacturing, Properties and Applications; Scheffler, M., Colombo, P., Eds.; Wiley-VCH: Weinheim, Germany, 2005; pp. 158-176, ISBN 978-3-527-31320-4.

9. Sandrolini, F.; Palmonary, P. Role of iron oxides in the bloating of vitrified ceramic materials. Trans. J. Brit. Cer. Soc. 1976, 75, 25-32. Available online: http://pascal-francis.inist.fr/vibad/index.php?action=getRecordDetail\&idt=PASCAL7688007289 (accessed on 2 July 2019).

10. Chen, C.; Lan, G.; Tuan, W. Microstructural evolution of mullite during the sintering of kaolin powder compacts. Ceram. Int. 2000, 26, 715-720. [CrossRef] 
11. Maniatis, Y.; Tite, M.S. A scanning electron microscope examination of the bloating of fired clays. Trans. Brit. Ceram. Soc. 1975, 74, 19-22. Available online: http://pascal-francis.inist.fr/vibad/index.php?action=getRecordDetail\&idt=PASCAL7688003524 (accessed on 20 May 2020).

12. Chinnam, R.; Francis, A.; Will, J.; Bernardo, E.; Boccaccini, A. Review. Functional glasses and glass-ceramics derived from iron rich waste and combination of industrial residues. J. Non-Cryst. Solids 2013, 365, 63-74. [CrossRef]

13. Petersen, R.R.; König, J.; Yue, Y. The mechanism of foaming and thermal conductivity of glasses foamed with $\mathrm{MnO}_{2}$. J. Non-Cryst. Solids 2015, 425, 74-82. [CrossRef]

14. Jordanov, N.B.; Hamzawy, E.M.A.; Tatchev, D.; Karamanov, A. Sintered Iron-Rich Glass-Ceramics and Foams Obtained in Air and Argon in: Foams-Emerging Technologies; Xu, H., Yang, C., Jing, D., Eds.; Intech Open: London, UK, 2020; pp. 71-85. [CrossRef]

15. Appendino, P.; Ferraris, M.; Matekovits, I.; Salvo, M. Production of glass-ceramic bodies from the bottom ashes of municipal solid waste incinerators. J. Eur. Ceram. Soc. 2004, 24, 803-810. [CrossRef]

16. Karamanov, A.; Hamzawy, E.M.; Karamanova, E.; Jordanov, N.B.; Darwish, H. Sintered glass-ceramics and foams by metallurgical slag with addition of $\mathrm{CaF}_{2}$. Ceram. Int. 2020, 46, 6507-6516. [CrossRef]

17. Fiocco, L.; Elsayed, H.; Daguano, J.; Soares, V.; Bernardo, E. Silicone resins mixed with active oxide fillers and Ca-Mg Silicate glass as alternative/integrative precursors for wollastonite-diopside glass-ceramic foams. J. Non-Cryst. Solids 2015, 416, 44-49. [CrossRef]

18. Strnad, Z. Glass-Ceramic Materials: Liquid Phase Separation, Nucleation and Crystallization in Glass Science and Technology; Elsevier: Amsterdam, The Netherlands; Oxford, UK, 1986; Volume 8, ISBN 0444415777.

19. Elmoutaouakkil, A.; Salvo, L.; Maire, E.; Peix, G. 2D and 3D characterization of metal foams using X-ray tomography. Adv. Eng. Mater. 2020, 4, 803-807. [CrossRef]

20. Goel, A.; Ferrari, A.M.; Kansal, I.; Pascual, M.J.; Barbieri, L.; Bondioli, F.; Lancellotti, I.; Ribeiro, M.J.; Ferreira, J.M.F. Sintering and crystallization behavior of $\mathrm{CaMgSi}_{2} \mathrm{O}_{6}-\mathrm{NaFeSi}_{2} \mathrm{O}_{6}$ based glass-ceramics. J. Appl. Phys. 2009, 106, 93502. [CrossRef]

21. Ljatifi, E.; Kamusheva, A.; Grozdanov, A.; Paunović, P.; Karamanov, A. Optimal thermal cycle for production of glass-ceramic based on wastes from ferronickel manufacture. Ceram. Int. 2015, 41, 11379-11386. [CrossRef]

22. Agea-Blanco, B.; Reinsch, S.; Müller, R. Sintering and Foaming of Barium Silicate Glass Powder Compacts. Front. Mater. 2016, 3. [CrossRef]

23. Karamanov, A.; Schabbach, L.M.; Karamanova, E.; Andreola, F.; Barbieri, L.; Ranguelov, B.; Avdeev, G.; Lancellotti, I. Sintercrystallization in air and inert atmospheres of a glass from pre-treated municipal solid waste bottom ashes. J. Non-Cryst. Solids 2014, 389, 50-59. [CrossRef]

24. Karamanov, A.; Paunović, P.; Ranguelov, B.; Ljatifi, E.; Kamusheva, A.; Načevski, G.; Karamanova, E.; Grozdanov, A. Vitrification of hazardous Fe-Ni wastes into glass-ceramic with fine crystalline structure and elevated exploitation characteristics. J. Environ. Chem. Eng. 2017, 5, 432-441. [CrossRef]

25. Stock, S.R. Recent advances in X-ray microtomography applied to materials. Int. Mater. Rev. 2008, 53, 129-181. [CrossRef]

26. Saparuddin, D.; Zaid, M.M.; Aziz, S.; Matori, K. Reuse of Eggshell Waste and Recycled Glass in the Fabrication Porous GlassCeramics. Appl. Sci. 2020, 10, 5404. [CrossRef]

27. Lazar, M.; Hnatko, M.; Sedláček, J.; Čarnogurská, M.; Brestovič, T. Upgrading the glassy slag from waste disposal by thermal plasma treatment. Waste Manag. 2018, 78, 173-182. [CrossRef] [PubMed]

28. Arcaroa, S.; Goulart de Oliveira Maia, B.; Souzaa, M.T.; Cesconetoa, F.R.; Granadosa, L.; Novaes de Oliveiraa, A.P. Ther-mal insulating foams produced from glass waste and banana leaves. Mater. Res. 2016, 19, 1064-1069. [CrossRef] 